\title{
Studies of Phase Diagram and Glass Transitions of a Liquid Crystal with Ferro- and Antiferroelectric Phases
}

\author{
Ł. $K_{\text {KoleK }}{ }^{a}$, M. Massalska-Arodź ${ }^{a}$, D. Majda ${ }^{b}$, B. Suchodolska ${ }^{c}$ And S. Zalewski ${ }^{c}$ \\ ${ }^{a}$ Institute of Nuclear Physics, Polish Academy of Sciences, E. Radzikowskiego 152, 31-342 Kraków, Poland \\ ${ }^{b}$ Faculty of Chemistry, Jagiellonian University, R. Ingardena 3, 30-060 Kraków, Poland \\ ${ }^{c}$ Institute of Chemistry, Siedlce University of Natural Sciences and Humanities, 3-go Maja 54, 08-110 Siedlce, Poland
}

\begin{abstract}
Based on the results of the differential scanning calorimetry, of transmitted light intensity measurements and of texture observations the phase diagram of 4-(6-heptafluorobutanoiloxyhexyloxy)biphenyl-4'-carboxylate(S)-4-(methyloheptyloxy-1-carbonyl)-phenyl (4H6) was obtained. The following phases were identified on cooling: isotropic, smectic A, smectic $\mathrm{C}^{*}$, smectic $\mathrm{C}_{\mathrm{A}}^{*}$ phases and a highly ordered phase called SmX and its glass. During heating transformation from glass of SmX to SmX phase and then transition to a metastable Cr2 phase, evolving to the more stable $\mathrm{Cr} 1$ phase, were observed. On further heating $\mathrm{SmC}_{\mathrm{A}}^{*}, \mathrm{SmC}^{*}$ and $\mathrm{Sm}$ phases were identified. When Cr2 was cooled, a glass transition was also observed.
\end{abstract}

DOI: 10.12693/APhysPolA.124.909

PACS: 64.70.kj, 64.70.mj, 64.70.pp

\section{Introduction}

Liquid crystals are substances built of anisotropic, mostly rod-shape molecules. For liquid-crystalline phases of some dipolar molecules tilted in smectic layers, the phenomenon of ferroelectricity was predicted in 1974 by Mayer et al. [1], basing on symmetry reasoning, and shortly after that observed. At 1989, features of the antiferroelectricity of MHPOBC compound were reported by Chandani et al. [2]. The properties of ferro- and antiferroelectricity of new synthesized chiral smectics as well as of the ferrielectricity in subphases occurring between them, are extensively explored to get better understanding of these phenomena. It is interesting from the fundamental point of view and important due to their potential applicability, especially in construction of ultrafast tri-stable liquid crystal displays of new generation [3-6].

The aim of this paper is to study thermal properties of 4-(6-heptafluorobutanoiloxyhexyloxy)biphenyl-4'-carboxylate(S)-4-(methyloheptyloxy-1-carbonyl)-phenyl,

abbreviated as $4 \mathrm{H} 6$ and to establish details of the phase diagram. The chiral carbon atom in molecular chain and non-zero electric moment perpendicular to the long axis of the molecule are the factors necessary for ferroelectric ordering.

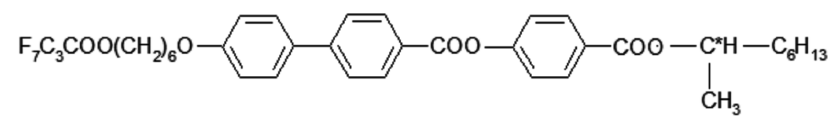

Fig. 1. Molecular structure of $4 \mathrm{H} 6$.

Figure 1 shows the molecular structure of the compound. We have chosen for our studies a substance where seven fluorine atoms are substituted for hydrogen atoms in one of the terminal chain. Studies of phase polymorphism were carried out using three complementary experimental methods: differential scanning calorimetry (DSC), texture observations using the polarizing microscope (POM) and the transmitted light intensity (TLI) measurements. Our goal was to check if the highly ordered liquid crystalline phases of $4 \mathrm{H} 6$ reveal a glass transition recently observed in $\mathrm{SmI}_{\mathrm{A}}^{*}$ of $1 \mathrm{~F} 7$ with the same chiral terminal group in the molecule [7].

\section{Experimental}

All measurements of $4 \mathrm{H} 6$ were performed with a substance synthesized at the laboratory of Prof. R. Dąbrowski group, Department of Chemistry, Military University of Technology, Warsaw. Calorimetric experiments (DSC) were carried out using a Mettler Toledo 822e differential scanning calorimeter. The heat flow signal $(\mathrm{d} Q / \mathrm{d} t)$, proportional to the difference between the power input to the sample and that of the reference, is registered as a function of time and of the sample temperature. The sample was closed in the aluminum vessel of $40 \mu \mathrm{l}$ capacity. The mass of the sample in DSC measurements was $17.35 \mathrm{mg}$. Molar mass of $4 \mathrm{H} 6$ is $742 \mathrm{~g} / \mathrm{mol}$.

Texture observations (POM) were performed using Biolar PI polarized microscope (PZO Warsaw) equipped with Linkam heating stage and the temperature controller and the Nikon objective. The sample put between the cover glasses was placed directly on a silver block heating stage in order to eliminate temperature gradients. The observed area was about $0.5 \times 0.4 \mathrm{~mm}^{2}$. The polarizing microscope was equipped also with camera connected with computer.

Complementary TLI method is a modification of the POM method, where the observer eye is replaced by the photodetector of very high sensitivity and of low "dark current", allowing to convert the light intensity into the current signal which can be precisely measured and collected in function of temperature. The magnitude of the 
recorded signal depends on the wavelength, which allows for detecting the subtle changes of a texture color $[8,9]$.

All the measurements were performed during both heating and cooling of the samples. The temperature values are given in degrees of Celsius for the convenience. Temperature range and the rate of temperature change were the following:

(i) from $-140{ }^{\circ} \mathrm{C}$ to $150^{\circ} \mathrm{C}$ and $2{ }^{\circ} \mathrm{C} / \mathrm{min}, 5^{\circ} \mathrm{C} / \mathrm{min}$, $10^{\circ} \mathrm{C} / \mathrm{min}, 20^{\circ} \mathrm{C} / \mathrm{min}$ in DSC measurements,

(ii) from $-25^{\circ} \mathrm{C}$ to $150^{\circ} \mathrm{C}$ and $1{ }^{\circ} \mathrm{C} / \mathrm{min}, 2{ }^{\circ} \mathrm{C} / \mathrm{min}$, $5^{\circ} \mathrm{C} / \mathrm{min}$ in TLI measurements,

(iii) from $-170{ }^{\circ} \mathrm{C}$ to $150^{\circ} \mathrm{C}$ and $0.5^{\circ} \mathrm{C} / \mathrm{min}, 1^{\circ} \mathrm{C} / \mathrm{min}$, $2{ }^{\circ} \mathrm{C} / \mathrm{min}, \quad 5^{\circ} \mathrm{C} / \mathrm{min}, \quad 10^{\circ} \mathrm{C} / \mathrm{min}, \quad 20^{\circ} \mathrm{C} / \mathrm{min}$, $50^{\circ} \mathrm{C} / \mathrm{min}, 100^{\circ} \mathrm{C} / \mathrm{min}$ in $\mathrm{POM}$ measurements (in the vicinity of phase transitions smaller rates of $0.1{ }^{\circ} \mathrm{C} / \mathrm{min}$ and $0.2{ }^{\circ} \mathrm{C} / \mathrm{min}$ were applied).

\section{Results and discussion}

In Fig. 2 the textures of eight phases observed by polarizing microscope during cooling and subsequent heating of $4 \mathrm{H} 6$ are shown. The sample was first heated to the isotropic phase and then cooled with a rate of $2{ }^{\circ} \mathrm{C} / \mathrm{min}$. On cooling the isotropic phase transforms at $129^{\circ} \mathrm{C}$ to paraelectric $\mathrm{Sm}$ phase. Then, the ferroelectric $\mathrm{SmC}^{*}$ and the antiferroelectric $\mathrm{SmC}_{\mathrm{A}}^{*}$ liquid crystalline phases were identified. During further cooling at $10^{\circ} \mathrm{C}$ small change in texture of the sample allowed us to discover a new phase, which we called SmX. On further cooling at about $-115^{\circ} \mathrm{C}$ cracks appeared in the image of the SmX phase texture. During heating cracks were gradually disappearing. At $T_{\mathrm{g}}$ the substance returns to the $\mathrm{SmX}$ phase with no cracks [10]. Then the substance proceeds to the metastable $\mathrm{Cr} 2$ phase and next to the more stable Cr1 phase. Further heating leads to the smectic phases; $\mathrm{SmC}_{\mathrm{A}}^{*}, \mathrm{SmC}^{*}$, and $\mathrm{Sm}$, respectively, and finally to the isotropic phase. When the Cr2 phase was cooled, intensive cracking process appeared in the image of its texture (and then on heating, decrease of number of cracks was detected) meaning that also the $\mathrm{Cr} 2$ phase was vitrified, presumably being a conformationally disordered crystal (CONDIS). No crystallization was detected on cooling a $4 \mathrm{H} 6$ compound.

DSC thermogram of $4 \mathrm{H} 6$ substance measured in the whole temperature range is presented in Fig. 3. The measurements were performed on cooling the substance from isotropic phase and then on heating. The monotropic system of thermodynamic phases observed using polarizing microscopy was confirmed. The exothermic process at about $10^{\circ} \mathrm{C}$ is a non-equilibrium phase transition as one can see from the parameters collected in Table. It can be interpreted as spontaneous ordering of the metastable $\mathrm{Cr} 2$ phase to a more stable $\mathrm{Cr} 1$ phase as was evidenced by change between two microscopic textures (compare Fig. 2c and $\mathrm{g}$ - between $\mathrm{Cr} 2$ and $\mathrm{Cr} 1$ no extra texture was observed). A similar process was observed by Kolek
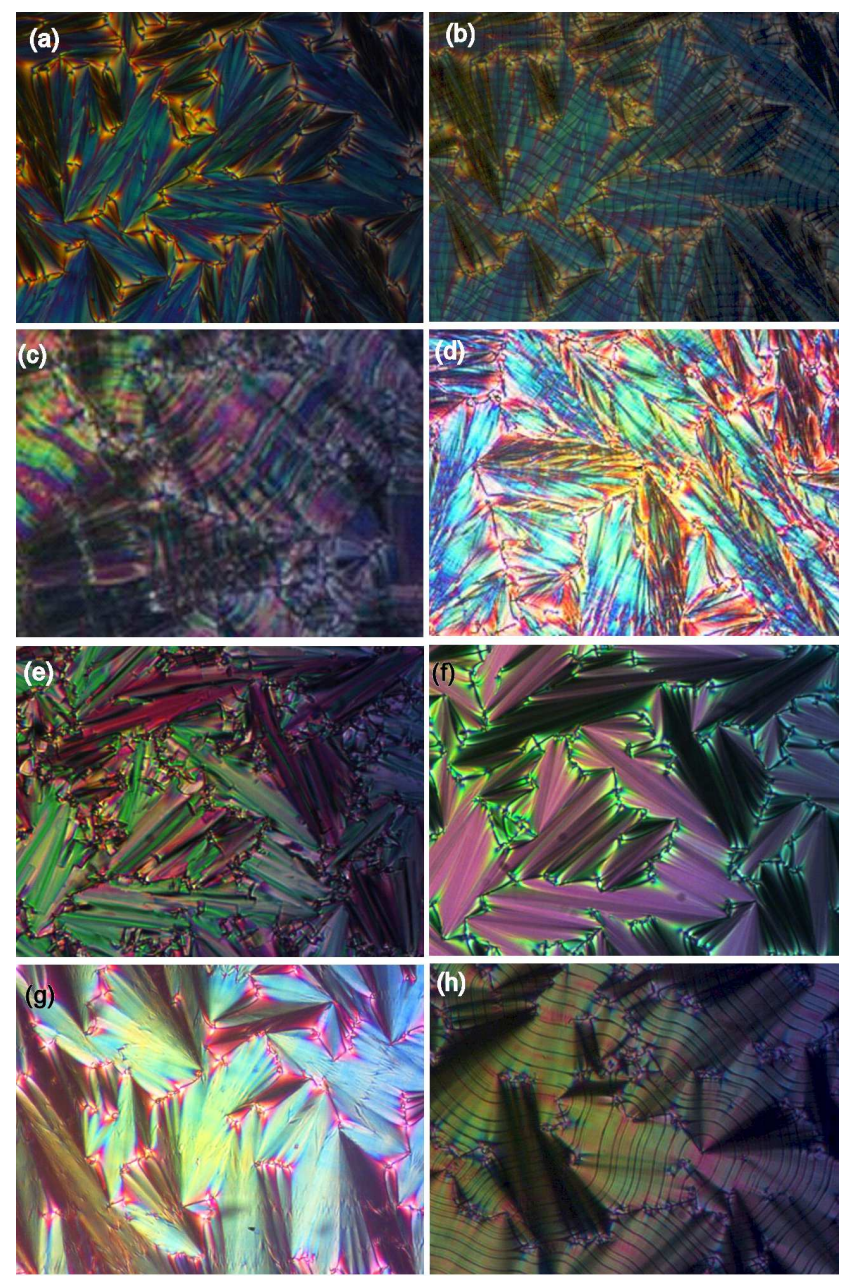

Fig. 2. Textures observed in the eyepiece of the polarizing microscope on cooling and heating the $4 \mathrm{H} 6$ sample with the rate of $2{ }^{\circ} \mathrm{C} / \mathrm{min}$ for: (a) SmX, (b) glass of $\mathrm{SmX}$, (c) Cr1, (d) $\mathrm{SmC}_{\mathrm{A}}^{*}$, (e) $\mathrm{SmC}^{*}$, (f) $\mathrm{Sm}$, (g) $\mathrm{Cr} 2$ and (h) glass of $\mathrm{Cr} 2$.

et al. for a substance $1 \mathrm{~F} 7$ with similar chiral molecular chain [7].

Based on the above thermogram (and more detailed checking in the vicinity of phase transitions) the following phase diagram was established during cooling

$$
\begin{aligned}
& \operatorname{Is}\left(129^{\circ} \mathrm{C}\right) \operatorname{Sm}\left(122^{\circ} \mathrm{C}\right) \operatorname{SmC}^{*}\left(111^{\circ} \mathrm{C}\right) \operatorname{SmC}_{\mathrm{A}}^{*}\left(10^{\circ} \mathrm{C}\right) \\
& \operatorname{SmX}\left(-50^{\circ} \mathrm{C}\right) \mathrm{GSmX}
\end{aligned}
$$

and during heating

$$
\begin{aligned}
& \operatorname{GSmX}\left(-50^{\circ} \mathrm{C}\right) \operatorname{SmX}\left(-18^{\circ} \mathrm{C}\right) \mathrm{Cr} 2\left(10^{\circ} \mathrm{C}\right) \mathrm{Cr} 1\left(30^{\circ} \mathrm{C}\right) \\
& \operatorname{SmC}_{\mathrm{A}}^{*}\left(112^{\circ} \mathrm{C}\right) \operatorname{SmC}^{*}\left(122^{\circ} \mathrm{C}\right) \operatorname{Sm}\left(130^{\circ} \mathrm{C}\right) \mathrm{Is} .
\end{aligned}
$$

The estimated values of the enthalpy and entropy changes at the phase transitions are collected in Table. The largest thermal effect during cooling was identified at the Is-Sm transition and is associated with appearance of a layered structure of molecules having tendency to be parallel. On heating the largest thermal effect was identified at the $\mathrm{Cr} 1-\mathrm{SmC}_{\mathrm{A}}^{*}$ transition, i.e., at the transfor- 


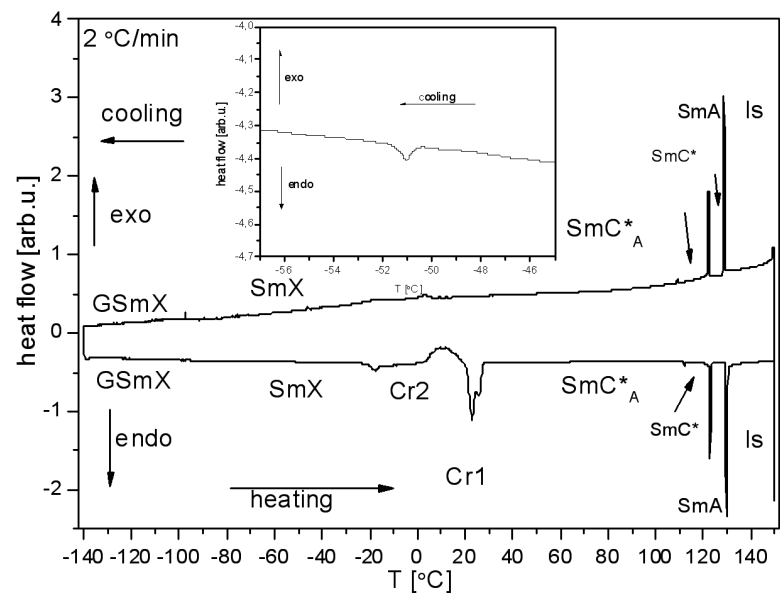

Fig. 3. DSC thermogram of $4 \mathrm{H} 6$ in the temperature range from $-140^{\circ} \mathrm{C}$ to $150{ }^{\circ} \mathrm{C}$ for heating and cooling with a rate of $2{ }^{\circ} \mathrm{C} / \mathrm{min}$. Inset graph shows anomaly near at $T_{\mathrm{g}}$ observed with a rate of $5^{\circ} \mathrm{C} / \mathrm{min}$.

mation between crystalline phase and a liquid-like phase with spiral antiferroelectric ordering. It is accompanied by activation of molecular and collective dynamics evidenced by dielectric spectroscopy [11].

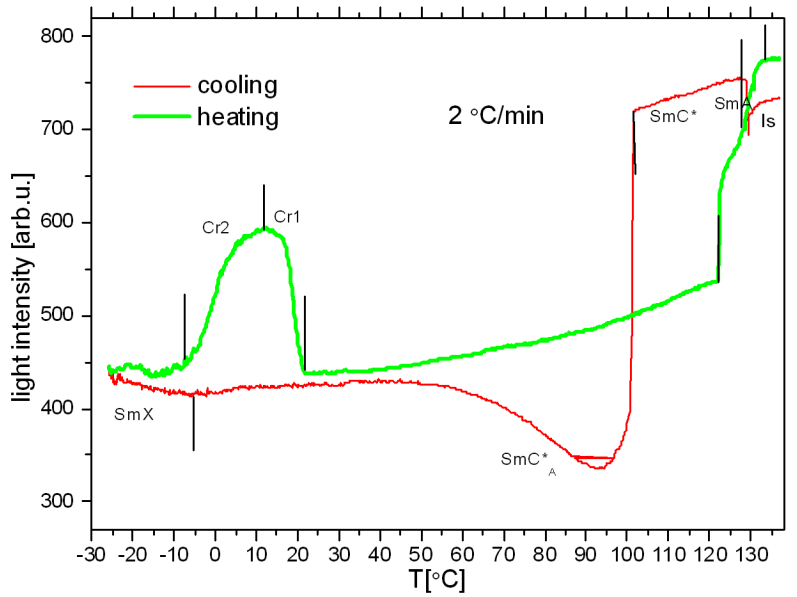

Fig. 4. Transmitted light intensity of $4 \mathrm{H} 6$ as a function of temperature in the range from $-25^{\circ} \mathrm{C}$ to $135^{\circ} \mathrm{C}$ for cooling and heating with the $2{ }^{\circ} \mathrm{C} / \mathrm{min}$ rate.

The results obtained for $4 \mathrm{H} 6$ in TLI measurements, performed in the temperature range from $-25^{\circ} \mathrm{C}$ to $135^{\circ} \mathrm{C}$, are presented in Fig. 4. Phase transition temperatures obtained from DSC thermogram are confirmed by TLI measurements.

Observations of textures under the polarizing microscope revealed a rich and complex phase polymorphism of the tested substance. It concerns especially a solid state, where two glassy phases (glass of SmX and glass of $\mathrm{Cr} 2$ ) were identified. On cooling of $\mathrm{SmX}$, appearance of cracks at about $-115^{\circ} \mathrm{C}$ followed each cooling run with rates applied from $1{ }^{\circ} \mathrm{C} / \mathrm{min}$ up to $50^{\circ} \mathrm{C} / \mathrm{min}$. Tempera-
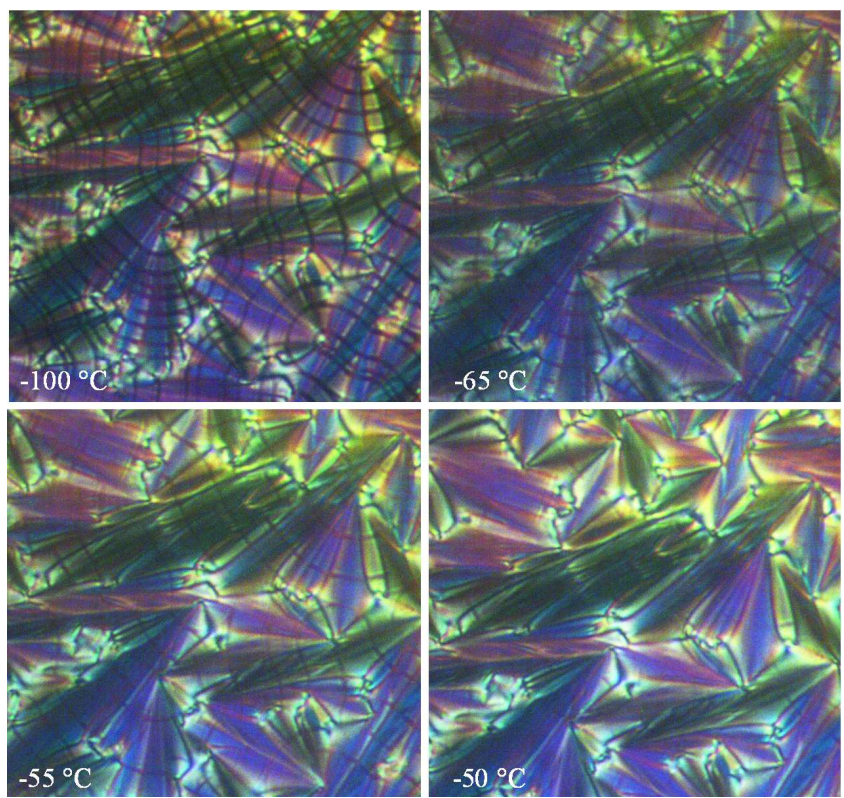

Fig. 5. Textures of glass of SmX phase observed in the eyepiece of the polarizing microscope on heating of $4 \mathrm{H} 6$ with the rate of $2{ }^{\circ} \mathrm{C} / \mathrm{min}$ at four temperatures.

ture of appearance of cracks was practically independent of the rate of cooling.

In Fig. 5 the sequence of textures of glass of SmX phase, showing diminishing of the cracks during heating of the sample with the pace of $2{ }^{\circ} \mathrm{C} / \mathrm{min}$, is presented. The last crack disappears at about $-50^{\circ} \mathrm{C}$, which we proposed in [10] as signature of glass transition on heating. In case of cooling the $\mathrm{Cr} 2$ cracks were observed at about $-112^{\circ} \mathrm{C}$. During heating cracks gradually disappear until a temperature of about $-55^{\circ} \mathrm{C}$, regarded as the temperature of transformation of glass of $\mathrm{Cr} 2$ phase (texture presented in Fig. 2h) to a metastable $\mathrm{Cr} 2$ crystal.

\section{Conclusions}

For 4H6 monotropic system of phases was found. Four enantiotropic liquid crystalline phases, i.e., the $\mathrm{Sm}$, the ferroelectric $\mathrm{SmC}^{*}$, the antiferroelectric $\mathrm{SmC}_{\mathrm{A}}^{*}$, and the $\mathrm{SmX}$ phases have been observed. On heating SmX phase crystallizes to metastable crystal $\mathrm{Cr} 2$ which evolves slowly to stable crystal $\mathrm{Cr} 1$ melting to $\mathrm{SmC}_{\mathrm{A}}^{*}$. The sequence of phases was established using three methods, i.e., light transmission intensity measurements, differential scanning calorimetry and polarizing microscope observations. Basing on the temperature of disappearance of cracks in textures observed on heating the heating the vitrified $\mathrm{SmX}$ and the vitrified $\mathrm{Cr} 2$ phases, $T_{\mathrm{g}}=-50^{\circ} \mathrm{C}$ and $T_{\mathrm{g} 1}=-55^{\circ} \mathrm{C}$, respectively, were found. 
TABLE

Values of the enthalpy and entropy changes at phase transitions observed during heating and cooling.

\begin{tabular}{c|c|c|c|c|c|c}
\hline \hline Process & Phase transition & $T\left[{ }^{\circ} \mathrm{C}\right]$ & $\Delta H[\mathrm{~J} / \mathrm{g}]$ & $\Delta H[\mathrm{~kJ} / \mathrm{mol}]$ & $\Delta S[\mathrm{~mJ} /(\mathrm{K} \mathrm{g})]$ & $\Delta S[\mathrm{~J} /(\mathrm{K} \mathrm{mol})]$ \\
\hline heating & $\mathrm{SmX}-\mathrm{Cr} 2$ & -18 & -0.79 & 0.58 & -3.09 & -2.29 \\
& $\mathrm{Cr} 2-\mathrm{Cr} 1$ & 10 & 7.57 & 5.62 & 26.74 & 19.84 \\
& $\mathrm{Cr} 1-\mathrm{SmC}_{\mathrm{A}}^{*}$ & 30 & -13.18 & -9.78 & -43.50 & -32.27 \\
& $\mathrm{SmC}_{\mathrm{A}}^{*}-\mathrm{SmC}^{*}$ & 112 & -0.07 & -0.05 & -0.18 & -0.13 \\
& $\mathrm{SmC}^{*}-\mathrm{Sm}$ & 122 & -1.97 & -1.46 & -4.99 & -3.70 \\
& $\mathrm{Sm}-\mathrm{Is}$ & 130 & -4.48 & -3.32 & -11.12 & -8.25 \\
\hline cooling & $\mathrm{Is}-\mathrm{Sm}$ & 129 & 6.02 & 4.47 & 14.97 & 11.10 \\
& $\mathrm{Sm}^{-}-\mathrm{SmC}$ & 122 & 2.13 & 1.58 & 5.39 & 4.00 \\
& $\mathrm{SmC}^{*}-\mathrm{SmC}_{\mathrm{A}}^{*}$ & 111 & 0.08 & 0.06 & 0.21 & 0.15 \\
& $\mathrm{SmC}_{\mathrm{A}}^{*}-\mathrm{SmX}$ & 10 & 0.59 & 0.44 & 2.08 & 1.55
\end{tabular}

\section{Acknowledgments}

The authors are grateful to Professor Roman Dabrowski and his group for synthesis of the substance. We would like to thank the Referee for suggestions which helped us to improve the paper.

\section{References}

[1] R.B. Mayer, L. Liebert, L. Strzelecki, P. Keller, J. Phys. Lett. 36, 69 (1975).

[2] A.D.L. Chandani, E. Gorecka, Y. Ouchi, H. Takezoe, A. Fukuda, Jap. J. Appl. Phys. 8, 1265 (1989).

[3] S.T. Lagerwall, Ferroelectric and ntiferroelectric Liquid Crystals, Wiley-VCH Verlag, Weinheim 1999.

[4] Z.Q. Liu, B.K. McKoy, S.T. Wang, R. Pindak, W. Caliebe, P. Barois, P. Fernandes, H.T. Nguyen, C.S. Hsu, S. Wang, C.C. Huang, Phys. Rev. Lett. 99, 077802 (2007).

[5] S. Haldar, K.C. Dey, D. Sinha, P.K. Mandal, W. Haase, P. Kula, Liq. Cryst. 39, 1196 (2012).
[6] M. Kaspar, V. Novotna, V. Hamplova, N. Podoliak, D. Nonnenmecher, F. Giesselmann, M. Glogarova, Liq. Cryst. 38, 309 (2011).

[7] Ł. Kolek, M. Massalska-Arodź, D. Majda, B. Wantusiak, S. Zalewski, P. Kula, Acta Phys. Pol. A 122 , 370 (2012).

[8] J. Chruściel, S. Zalewski, M.D. Ossowska-Chruściel, A. Filiks, A. Rudzki, in: Complementary Methods of the Phase Transitions Studies, Jagiellonian University Press, Cracow 2003, p. 247.

[9] M.D. Ossowska-Chruściel, S. Zalewski, A. Rudzki, A. Filiks, Chruściel, J. Phase Transit. 79, 679 (2006).

[10] M. Jasiurkowska-Delaporte, E. Juszyńska, Ł. Kolek, J. Krawczyk, M. Massalska-Arodź, N. Osiecka, T. Rozwadowski, Liq. Cryst. 40, 1436 (2013).

[11] Ł. Kolek, M. Massalska-Arodź, K. Adrjanowicz, "Dynamics in crystalline and liquid-crystalline phases of $4 \mathrm{H} 6$ as studied by dielectric spectroscopy", in preparation. 